\title{
Efficacy of the Volleyball Game Actions Related to the Quality of Opposition
}

\author{
Rui Marcelino $^{1, *}$, Isabel Mesquita ${ }^{1}$ and Jaime Sampaio ${ }^{2}$ \\ ${ }^{1}$ Centre of Research, Education, Innovation and Intervention in Sport (CIFI2D), Faculty of Sport - University of Porto, \\ Portugal \\ ${ }^{2}$ Research Center in Sport Sciences, Health and human Development (CIDESD), University of Trás-os-Montes e Alto \\ Douro at Vila Real, Portugal
}

\begin{abstract}
Game analysis has an important role on the description of 'what happens' in competitions and should reach the ability to suggest new ways to enhance sport performances. In order to accomplish this goal is important that possible factors enables to influence these performances were considered. Quality of opposition is one of these factors. In this study, TwoStep Clusters analysis was used to classify group teams participated in FIVB Men's World Cup 2007 into competitive levels. The results show three different competitive levels $\left(\left[1^{\text {st }}-4^{\text {th }}\right],\left[5^{\text {th }}-7^{\text {th }}\right]\right.$, and $\left.\left[8^{\text {th }}-12^{\text {th }}\right]\right)$. Chi-square tests were used to show the influence of quality of opposition, i.e. games against teams of different competitive levels, in the efficacy of some game actions (serve, attack and block). Results showed that the quality of the opposition influence the performance in some game actions.
\end{abstract}

\section{INTRODUCTION}

The quality of opposition has been suggested to have an important influence on sport performance. However, there are scarcities of specific studies that have this possible influence as main goal. The quality of opposition was frequently dichotomized into "strong" and "weak" [1], based on the symmetric division of teams based on the final ranking, i.e. top or bottom half of the ranking, and teams were categorized as "successful" or "unsuccessful" [2], based on their progress within a particular tournament. Both of these categorizations were problematic since, in on hand, the groups could be formed by too many teams without clear differences between them, and in other hand, a team deemed to be successful may not necessarily be of high quality and vice versa [1].

The purpose of the current study was to analyze the efficacy of the Volleyball game actions (block, attack and serve) related to the quality of the opposition on the high competitive level.

\section{METHODS}

Twenty five matches (corresponding to eighty nine sets) played in the FIVB Men's World Cup 2007 were sampled from a total of sixty six matches played. To ensure representativity, all the twelve teams' participating in the competition, were sampled a minimum of three and a maximum of five matches of each team.

The variables were the efficacy of the game actions and the quality of opposition. The efficacy was presented in a scale of 5 or 6 qualitative points, namely: serve (as described

*Address correspondence to this author at the Centre of Research, Education, Innovation and Intervention in Sport (CIFI2D), Faculty of SportUniversity of Porto, Portugal; E-mail: rui_barroselas@hotmail.com in [3]), attack (as described in [4]), and block (as described in [5]). All the games were video recorded with a digital camera located approximately $15 \mathrm{~m}$ above the playing field and approximately $20 \mathrm{~m}$ back the edge of the field, parallel with the baseline.

To establish the quality of opposition a TwoStep Cluster analysis (Distance Measure: Log-likelihood; Clustering Criterion: Schwarz's Bayesian Criterion) was used to classify the teams into groups according to their competitive levels. The number of clusters was fixed in three as recommended by Taylor and co-workers [1] and the variables used for the calculation were: Points in the final of competition, Ratio of total number of points won and lose, Ratio of total of sets won and lose, Percentage of sets won. The first cluster (Level 1) was constituted by the first four final classifications teams $\left[1^{\text {st }}-4^{\text {th }}\right]$, second cluster (Level 2) was constituted by fifth, sixth and seventh final classifications teams $\left[5^{\text {th }}-7^{\text {th }}\right]$, and the last cluster (Level 3) was constituted by the five last final classifications teams $\left[8^{\text {th }}-12^{\text {th }}\right]$.

Observation and evaluations of the variables of the study were performed by four teams of two trained observers. Each team observed a minimum of five games and a maximum of 8 games. One of the observers was responsible for the data insertion on the computerized notational analysis system (VROS - Volleyball Rally Observation System) and the other was responsible for the necessary playback, slow motion and fix images in the digital video viewer used (utilius ${ }^{\circledR}$ fairPLAY, CCC-Software, Germany). Data reliability was assessed through intra- and inter-observer testing procedures [6]. Following a 3-week period, to go against any learning effect, each observation team have re-analysed one random game of all that they have observed. For completed inter-observer reliability testing, each observation team observed one game previously analyzed by other observation team. The data were compared with those of the original 
Table 1. Differences of Efficacy on Serve, Attack and Block, According to Quality of Opposition

\begin{tabular}{|c|c|c|c|}
\hline & Serve $^{1}$ & Attack & Block \\
\hline Level 1 & Chi-square $(8)=29.73 ;$ Phi $=0.11 ; p<0.01$ & Chi-square $(10)=13.64 ; \mathrm{Phi}=0.08 ; \mathrm{p}=0.19$ & Chi-square $(10)=15.71 ; \mathrm{Phi}=0.16 ; \mathrm{p}=0.11$ \\
\hline Level 2 & Chi-square $(8)=26.17 ;$ Phi $=0.16 ; \mathrm{p}<0.01$ & Chi-square $(10)=11.19 ; \mathrm{Phi}=0.11 ; \mathrm{p}=0.34$ & Chi-square $(10)=12.76 ; \mathrm{Phi}=0.20 ; \mathrm{p}=0.24$ \\
\hline Level 3 & Chi-square $(8)=12.03 ; \mathrm{Phi}=0.09 ; \mathrm{p}=0.15$ & Chi-square $(10)=35.91 ; \mathrm{Phi}=0.16 ; \mathrm{p}<0.01$ & Chi-square $(10)=31.39 ;$ Phi $=0.29 ; \mathrm{p}<0.01$ \\
\hline
\end{tabular}

${ }^{1}$ The Chi-square and effect size (Phi) values presented correspond to the test against all quality of opposition. i.e. "Chi-square(8)=29.73;Phi=0.11;p<0.01" are the values of Level 1 teams efficacy on serve in games played against teams of Level 1, Level 2 and Level 3.

coding sessions. Intra- and inter-observer agreement were assessed via the percentage error method advocated by Hughes and co-workers [7], with all data found to be within acceptable levels (i.e. $<5 \%$ error). To test the association between the quality of oppositions and the efficacy of the serve, attack and block Chi-square test was used. Test has applied in each possible scenario of quality of opposition (Level 1 against Level 1, Level 1 against Level 2, Level 1 against Level 3, Level 2 against Level 1, Level 2 against Level 2, Level 2 against Level 3, Level 3 against Level 1, Level 3 against Level 2, Level 3 against Level 3). Effect-size [8] test (Phi) were also performed to show the weight of the associations exposed by Chi-square tests. Analyses were carried out using the statistical program SPSS for Windows, version 17.0 (SPSS Inc, USA) and statistical significant was set at $\mathrm{P}<0.05$.

\section{RESULTS}

Results showed that teams of level $1\left[1^{\mathrm{st}}-4^{\text {th }}\right]$ and teams of level $2\left[5^{\text {th }}-7^{\text {th }}\right]$ had different serve performance according to the competitive level of their opponents (Table 1). However for these two competitive levels (1 and 2) neither attack efficacy nor block efficacy showed variations accordingly to the quality of opposition.

Teams of level $3\left[8^{\text {th }}-12^{\text {th }}\right]$ showed a significant association between the quality of opposition and the efficacy of attack and block.

For all significant results only the association between teams of level 3 and block efficacy was moderate [9]. All the other showed a weak association.

\section{DISCUSSION}

Game analysis has an important role on the description of 'what happens' in competitions and should achieve the ability to suggest tracks to enhance sport performance. The present study shows that the quality of opposition could differentiate the efficacy of the games actions. These results are dissonant with those of Taylor and all. [1] where variations in behavior incidents were independents of the quality of the opposition. The authors argue with the reductionism of "strong-weak dichotomy" used for classifying the quality of opposition as a possible justification for the findings. Our study, by means of a strategy that integrate different performance indicators to organize competitive levels groups, showed that could be a good tenet to determine the quality of opposition. Indeed, based on this procedure, the study showed different patterns according to the specificity of the game actions and the quality of the opposition. While the efficacy of the serve varied for the level 1 and 2 teams, the efficacy of the attack and block was different for the teams belonging to the level 3 . In further research it will be interesting to find out if this tendency occurs in other variables, namely setting, serve-reception and dig.

\section{REFERENCES}

[1] Taylor J, Mellalieu S, James N, Shearer D. The influence of match location, quality of opposition, and match status on technical performance in professional association football. J Sports Sci 2008; 26(9): 885-95.

[2] Hughes M, Churchill S. Attacking profiles of successfull and unsuccessfull teams in Copa Amareica 2001. In: Reilly T, Cabri J, Araújo D, Eds. Science and football V. Abingdon: Routledge 2005: pp. 219-24.

[3] Rocha C, Barbanti V. An analysis of the confrontations in the first sequence of game actions in Brazilian volleyball. J Hum Mov Stud 2006; 50(4): 259-72.

[4] Marcelino R, Mesquita I, Sampaio J. Sequential analysis in Volleyball attack performance: a log-lineal analysis. J Sport Sci 2008; 26(Supp2): S83-S4.

[5] Palao J, Santos J. Effect of the Setter's Position on the Block in Volleyball. Int J Voll Res. 2004; 6(1): 29-32.

[6] James N, Taylor J, Stanley S. Reliability procedures for categorical data in Performance Analysis. Int J Perform Anal Sport 2007; 7: $1-11$.

[7] Hughes M, Cooper S, Nevill A. Analysis of notation data: reliability. In: Hughes M, Franks I, Eds. Notational analysis of sport: systems for better coaching and performance in sport. $2^{\text {nd }}$ ed. Abingdon, UK: Routledge 2004; pp. 99-107.

[8] Drinkwater E. Applications of confidence limits and effect sizes in sport research. Open Sports Sci J 2008; 1: 3-4.

[9] Kotrlik J, Williams H. The incorporation of effect size in information technology, learning and performance research. Inform Tech Learn Perform J 2003; 21(1): 1-7. 